\title{
National and international components in contemporary architecture and design
}

\author{
Aleksandrina Mikhailova1[0000-0002-2238-5189]*, Sergey Mikhailov ${ }^{10000-0002-4306-7948]}$, \\ Lilia Khousnutdinova ${ }^{1[0000-0001-8542-5697]}, \quad$ Anastasia Ibragimova ${ }^{10000-0002-6552-5380]}$, and \\ Maksim Belov ${ }^{10000-0001-5204-2008]}$ \\ ${ }^{1}$ Kazan State University of Architecture and Engineering, 420043 Kazan, Russia
}

\begin{abstract}
The article examines one of the unique aspects of design - the national component. The history of design demonstrates to us the importance of the national component in the formation of object-based shaping, its development in the industrial and post-industrial eras. In the conditions of post-industrial design, the role of the national component is growing and is increasingly revealed in its various directions, from object design to design of the urban environment. Through the prism of the interaction between national and international components in design, we can scrutinise design's entire history. Using specific examples, applying phenomenal-geographical and synergetic approaches, the authors formulate the main models of the evolution of the national component in the design of different countries. As a result, 6 models of interaction of the national and international components in the subject design of the twentieth century were identified. They are «the constant of the national component», «transformation (expansion) of the national component into the international», «synchronization of the national and international components», «replacement of the national component with the international», «conglomeration of international and national components», «autonomy of national and international components». Graphic visualizations of models of countries - design nations are presented on the example of Japan, USA, Germany, Italy and Scandinavia.
\end{abstract}

Keywords. National component in design, style in design, design icon, design history, synergistic approach in design, phenomenal geographical approach.

\section{Introduction}

The national component in design appears in various forms. This variety causes interest of many researchers in several aspects. Firstly, it is a process of interaction between traditional handicraft production and industrial design. Secondly, it is a phenomenon of design development in some countries. Thirdly, it is a valuable foreign experience of producing its own strategy for the development of domestic design. It is difficult to overestimate the importance of the national component in the formation of subject-matter formation in the industrial era. Many design objects, which are originally were presented as unified and accessible, also meant to fit into any style. However, on practice it turns out that they contain

${ }^{*}$ Corresponding author: misuoka@gmail.com 
a national component. Others, seemed to be national objects, after a while become common in various countries. That endows them with an international quality, without changing their essence. Such kind of instances make us thinking about the importance of studying the issue of the national and international components in design. This importance increases within the framework of post-industrial design. After a long process of globalization, we are finally witnessing the development of the trend of cultural differentiation and the appeal of modern design to ethnocultural and national issues.

Modern researchers distinguish several countries that have made a significant contribution to the overall development of industrial shaping. That made it in the way of master-piecing design activity or has taken an active part in the evolutionary process of style formation and have successfully declared themselves on the world market, calling them «design nations». Among them are Germany, England, USA, Italy, Japan, Scandinavia. The contribution of these «design nations» can also be assessed quantitatively - by the number of iconic objects that have enriched history with world-famous brands that are used by art critics and historians to describe the world design history. At the same time, it should be noted that these countries throughout history did not necessarily pass on the baton of influence to each other on the world stage of design development. Sometimes their contribution was limited just for some bright and very significant periods (VKHUTEMAS (Higher Art and Technical Studios) and constructivism in Russia, Bauhaus in Germany), sometimes it persists for a long time (Scandinavia, Japan). There are several main approaches to the national component in the design of different countries: succession, organic integration of the national component; denial of the national component, tendency of internationalization, abstraction and generalization; bringing back to the roots, reinterpretation of traditions through industrial technologies, and, as a result, a new look at the national shaping.

The problem of «national and international components» in design becomes more and more topical nowadays. They discuss different questions of national identity in design [1]. For instance, the combination of cultural identity and technological realism [2], the impact of globalization process on a national identity [3] and national and international components, depending on the relationship of form and function [4]. One of the vectors sufficiently highlighted in this direction is the relationship between architecture and industry $[5,6]$, national identity in architecture [7, 8], as well as ethnoreligious identity [9]. A number of art critics turn to a narrower field of research related to the formation of cultural identity in certain areas - the design of the urban environment [10], the industrial design [11], as well as to the history of design and architecture [12-14]. But the most widespread, of course, are studies of design issues in individual countries, for example, Scandinavian $[15,16]$. In studies, their phenomenon is revealed in many aspects, issues of culture, lifestyle, fashion $[17,18]$, both from a historical perspective, and their current state and impact on the world design and artistic culture [19-21] are raised. Moreover, in the 2000-2010 interest was largely focused on design nations - Germany, France [23], scandinavian countries [24], Italy [25], while as at present, researchers are interested in other countries that have not shown themselves so clearly and openly in the history of design, but nevertheless have their own originality [26-28].

\section{Methods}

The object of the research is the «national component» in subject-based shaping in the conditions of industrial production, which demonstrates it's belonging to a nation, having distinctive character, originality, reflecting a way of life, worldview, mentality and traditions of shaping. The national component makes it possible to identify the products of industrial shaping according to a number of characteristics (colour, shape, material and function, etc.), 
which were formed under the influence of various factors: socio-political, socio-economic, scientific and technical, socio-cultural and artistic and stylistic.

The systemic method is used as fundamental in the process of work, which became decisive for identifying and disclosing the concept of «national component» and its analysis. As well as a retrospective analysis aimed at identifying the formation of the national component at various stages in the history of design development in the XX-XXI centuries. In addition, the work uses the phenomenal-geographical principle of describing the history of design On the one hand, the study is based on a fairly detailed multivariate analysis of iconic design objects by country and continent, on the other hand, there is a desire to preserve the integrity of the overall historical picture.

\section{Results and discussion}

\subsection{The national component in the design of the industrial era}

At first glance, the answer to the problem of national and international components in architecture and design posed in the article is obvious and lies in the name itself. It is enough to change the places of the words and we get something that satisfies everyone: «national in architecture and international in design». Industrial design has no nationality; mass production makes it international. However, this simplicity of the answer is only apparent.

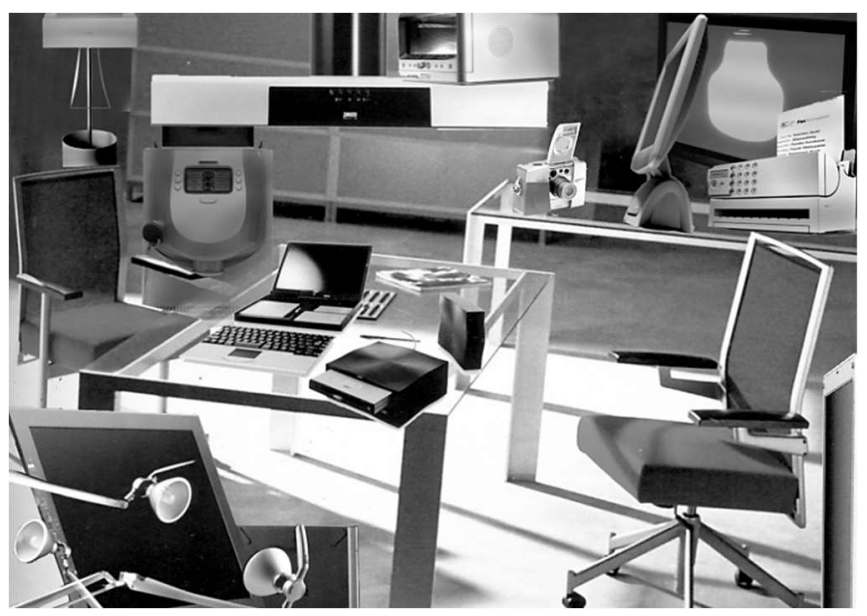

Fig. 1. Design objects of the industrial era.

Unlike the architecture, design can be observed completely different, often directly opposite situations. For instance, today in our everyday life we face an amazing phenomenon: products of different manufacturers, created in different countries, not only peacefully coexist in our interiors, but sometimes harmoniously combine with each other, forming a stylistically single whole. The design of the TV made in Japan in terms of colours, as well as the general compositional methods of constructing the form itself, the typefaces used in the design, harmonize with the adjacent CD player from Germany and the sound amplifier of the company Philips from Netherlands. Popular American jeans go well with the newest stylish Italian blouse, Portuguese moccasins paired with a youth bag from Turkey. You involuntarily catch yourself thinking that all this is done with one hand, one brand. The answer to this question lies in understanding the very essence of design, which originally arose as a means of increasing the competitiveness of industrially manufactured products. They are increasing the aesthetics of their appearance and improving consumer qualities. Hence the focus of 
design on the latest materials and technologies, on modern fashion and consumer tastes. It is the modernity of the appearance of the products and fashion that ultimately unite them stylistically. Thus, we can state that industrial design, designed for a wide range of consumers, is inherently international and does not have a specific national identity (fig. 1) [29].

For the consumer today, the question of «what country the product is from» is not as important, as the question «what company has produced it». Appeared in a particular country and gained wide popularity in the market, such a company should represent not only its image, but also define a kind of visiting card of the country, becoming a kind of visiting card, and in some cases, national pride. Such companies are Philips in the Netherlands, Sony in Japan, Parker in the United States.

\subsection{The bearer of the national component in design is the consumer}

Comparing the modern interiors of the house of German, Japanese or American, we see that they are strikingly different, despite the fact that they sometimes contain completely identical objects. The individuality of its residence in the conditions of mass circulation of its components is created by the owner. They become the bearer of the national component. National component itself is passed down from generation to generation in the way of traditions and customs, as the form of its own language and culture, which have been preserved for centuries and are tremulously guarded.

The surviving customs and traditions are associated with national characteristics: Italian coffee, English tea, German beer, French wine, Uzbek pilaf, etc. These traditions and customs often become a kind of motive for the industrial production of products specific to a particular country or place (fig. 2) [30].

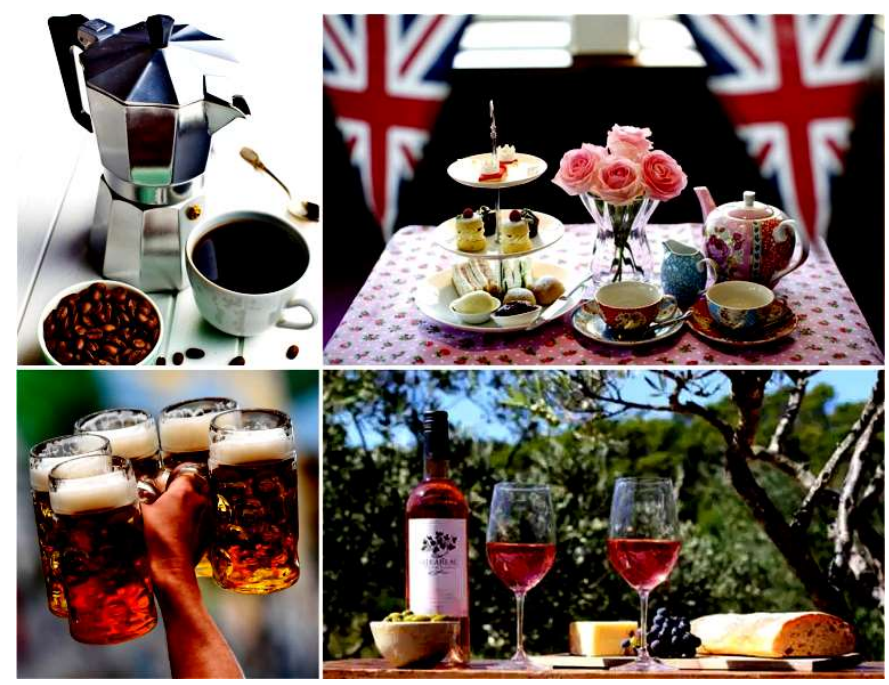

Fig. 2. The surviving customs and traditions are associated with national characteristics.

\subsection{The manifestation of the national component in the design of the urban environment}

The task of forming an individual and distinctive image is also important in the organization of urban environment. Primarily, commercially produced elements are used today: benches, bins, street lighting poles, billboards, kiosks and shopping modules. By designing street equipment, we can identify the features and uniqueness of the existing architectural and 
landscape context, or, on the contrary, we can level the architectural and artistic image of an urban planning ensemble, destroying its individuality.

The formation of a bright, memorable environment with individual features (including national ones) based on the use of an arsenal of modern design means is one of the main design features of the architectural environment.

In the process of solving this problem, the architects and designers often use the «method of corporate identity». However, unlike the industrial design we know, it is not the corporate identity of the enterprise that is formed here, but the individual local style of the architectural ensemble, relying largely on the design tools of the urban environment (small series of industrially manufactured street furniture, visual communications, etc.). Unlike historical artistic styles known to us from the history of architecture, which are objective in nature, such a local style is set by one designer or a group of authors and, as a result, is subjective.

\subsection{The national component in the design of urban environment also manifests itself in detail}

For example, in the formation of urban sculpture, a national component is an integral factor that presents at absolutely different stages of the creation and existence of a sculpture object. The most striking manifestations of national component usage in our opinion are 1) the emphasis on national, local events, 2) the importance of individual characteristics of a person in identifying their national characteristics, 3 ) in the actualization of the urban environment, which manifests itself with the intensified popularization of sculpture. Sculpture itself is public domain and directly associated with the place where it is located.

As an example, when we are talking about a sculpture with the national component in it and it reveals the events that took place in a given area, I would like to note the work of Peter Eisenman «Memorial to the Murdered Jews in the Holocaust». This memorial ensemble is ideally embedded in the fabric of the city and in fact is a metaphor for the national situation in Germany and national grief of the Jewish people. The viewers who have found themselves in the environment of these memorial steles feel incredible helplessness, loneliness and at the same time, imbued with the national history, develop such qualities as humanity, sorrow, and understanding.

In the work of Jaume Plensa «Crown Fountain» (2004), the national component plays an important role, broadcasting the individual national characteristics of a person. The fountain, was installed in 2004 in the centre of Chicago, in the form of two media-facade parallelepipeds located opposite each other. They are huge faces residents of Chicago different nationalities, races, age and gender. Each face is depicted - individually, colourful, with a peculiar facial expressions and emotions - is an impressive task of this object of the urban environment to demonstrate the beauty and ethnic diversity of the city.

Highlighting the role of the national component in the actualization of the urban environment, is worth noting such a phenomenon when using the images of significant sculptural objects, the city gains new popularity and thus a new significance of national colour. A striking example is Prague, which even before the beginning of the $21^{\text {st }}$ century was visually associated only with the Charles Bridge and the chimes on the main square. Today it is almost the European capital of original sculptures. This is not accidental, because today within the framework of developed information technologies, imprinting, for example, a sculpture object in social networks, Internet communities, news, automatically raises the object to the rank of a business card of a place, and its geographic mark only stimulates this process. The work of David Cerny «The Head of Franz Kafka» installed in the centre of Prague in 2014, is a prime example of this. Black, using kinetic techniques, makes the head of the German writer move, 
blending in with a unique concept. This sculpture is so popular that it is the hallmark of the city and in fact its national treasure, attracting tourists and harmonizing the urban space.

A large number of similar objects popularizing the cities of the world have been installed over the past decade. Each of these sculptures enriches the figurative and national identity of the places in which they are installed. In other words, it turns out that the national, local character is focused in the objects of the environment and in the future is directly associated with them.

\subsection{Development of the national component in the post-industrial era}

In the XXI century, the concept of «post-industrial design» appeared. One of its priority tasks was the search for means of diversity, individualization and uniqueness of the appearance of the products. One of these means of individualization was a return to the roots, an appeal to national origins in shaping.

The development of design in a number of countries was associated with the renaissance of national craft traditions and the accentuation of national flavour. The search for new forms of shaping (materials, style-forming, ensemble, etc.) frequently, even in the conditions of industrial design, were carried out on the territory of the national craft. To date the potential of national traditions as a source of design creativity has not yet been exhausted. Moreover, there is a need to understand the revival of the basic semantics of national cultures. This circumstance actualizes the problem of the existence of national and cultural models of modern design [32].

\subsection{Models of evolution of the national component}

Based on the fact of the formation of design in a number of countries in the context of its interaction with traditional craft shaping, it is possible to trace the evolution of the development of the national component in the history of industrial shaping of the $20^{\text {th }}$ century.

As a result, 6 models of various forms of implementation and interaction of national and international components in the subject design of the twentieth century were developed $[27,28]$. Some of them demonstrate a certain continuity, organic weaving of the national component into modern design, while other models are built on the principle of denying the national component, reflect the desire for internationalization, abstraction, generalization. Moreover, it is possible to trace a return to the roots, a rethinking of traditions through industrial technologies, and, as a consequence, a new look at the «national formation»[33].

\subsection{1 $1^{\text {st }}$ model - «Constant of the national component»}

This model implies the constant existence of a bright national line in shaping, regardless of the type of production. First of all, these are countries with a bright national flavour and due to some circumstances with a predominant handicraft or poorly developed industrial production. Such a model is largely consistent with, for example, Mexico, Brazil or African countries, whose handicraft is known for its vivid ethnic images and inspired many artists and designers, but nevertheless industrial design in these countries is still poorly represented. We observe a partial similar manifestation in the colonial style - a kind of synthetic interaction between the mentioned national culture and European form-building. Graphically, the model «constant of the national» can be shown as a linear form of the development of national handicrafts (fig. 3). 

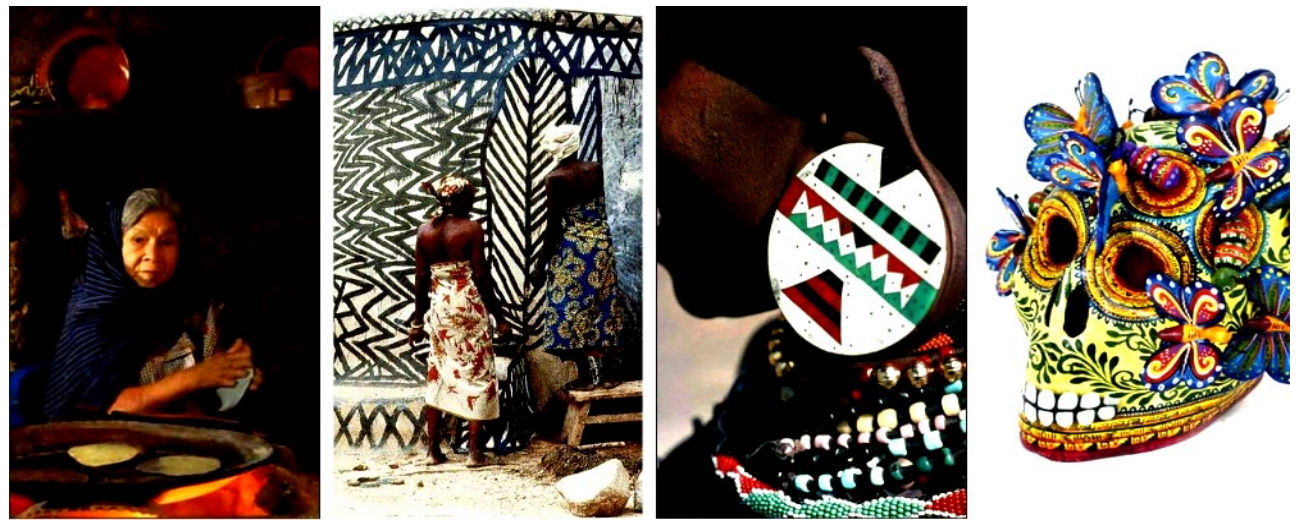

Fig. 3. Traditional cooking by Mexican women. Traditional village structure from Tiebele, West Africa. The Zulu Nation of South Africa. Alfonso Castilio Horta.

\subsection{2 $2^{\text {nd }}$ model - «Transformation (expansion) of the national into the international»}

In this model, a clear line of national shaping is traced, the basic techniques of which become the basis of industrial design. In such facilities, the national component is especially felt in the output, and at the same time it conquers the world market, becomes international, without losing its original «ethnic».
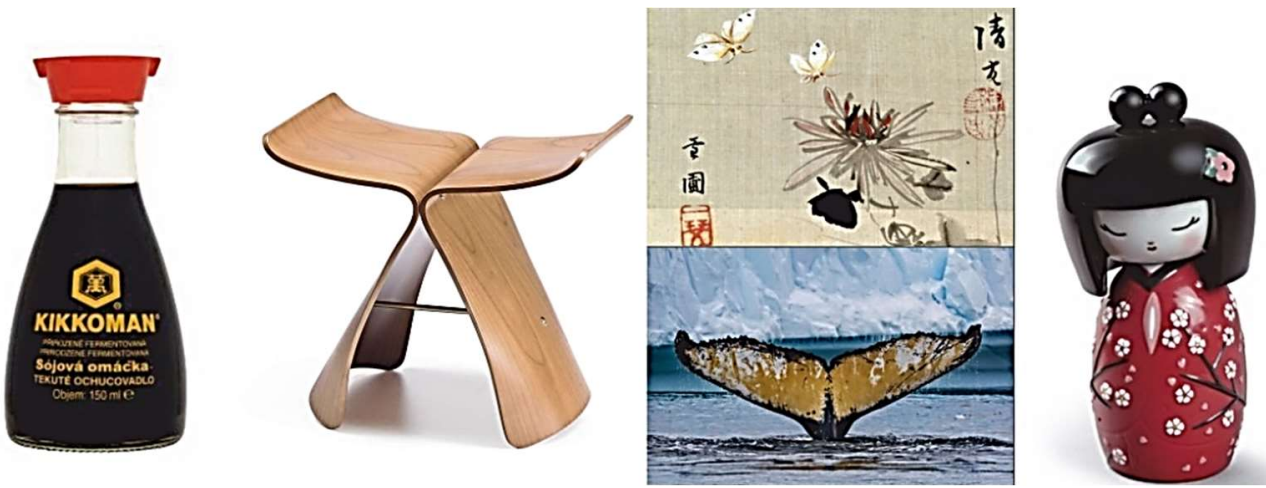

Fig. 4. Bottle of Kikkoman soy sauce, stool «Butterfly» by Sori Yanagi in comparison with the shape of a butterfly from an engraving by J. Baitsu (c. 1840) and the shape of a whale's tail, traditional Japanese kokeshi mascot doll.

One of the most striking examples of the implementation of this model is Japan. Connection with tradition is one of the specific features of Japanese design, it is carried out at different levels. Firstly, at the level of full adherence to traditional technologies and design methods, secondly, at the level of creative processing of cultural heritage and revealing its principles through the latest achievements of the world design and artistic culture, and finally at the level of approach to the design process. The identified levels indicate the presence of three main trends in Japanese design: national, mixed and international - they existed and exist in parallel, consistently developing and improving. The experience of Japan in this sense is very indicative, based on the philosophical and worldview principles of the unity and harmony of a person with the world around it. Japanese design embodies these ideas in modern objects, which allows them to be successful around the world without losing their 
culture of identity [9]. Graphically, the expansion of the national into the international is a wave-like structure, and in the case of Japan, its spiral subtype, which also correlates with the spiral development of the Japanese economy [34] (fig. 4).

\subsection{3 $3^{\text {rd }}$ model - «Synchronization of national and international components»}

This model synthesizes a new look, a new reading, a new modern approach to the national, which is adapted to modern needs and translated into the international. The international often turns to the original roots of the national handicraft in search of new ideas, motivation and inspiration. These are countries with a strong influence of traditional handicraft shaping and a developed industry. In this type, industrial design is constantly fuelled by the ideas of traditional craft shaping. The graphic display of such a model can be branched or sinusoidal with different amplitude fluctuations. According to this scenario, design is being developed in Scandinavia and Italy. Scandinavian shaping is unique in nature, its features are the use of natural materials, natural forms, lightness, deliberate modesty, simplicity, respect for craftsmanship and traditions. The aesthetics of Scandinavian modernism influenced the world design culture of the mid and late $20^{\text {th }}$ century the most. It changed not only things, but it also became the model for a new European lifestyle (fig. 5).
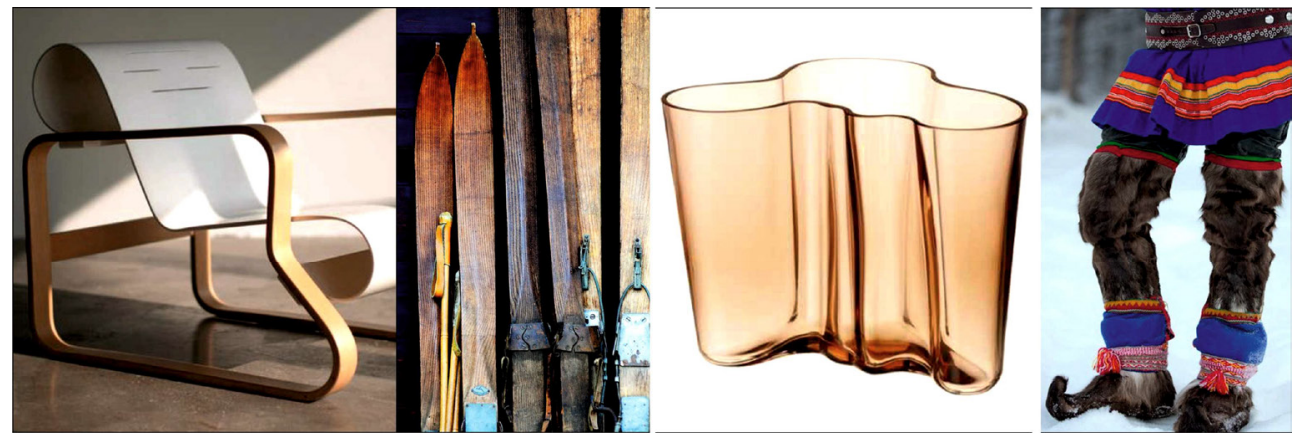

Fig. 5. A. Aalto «Armchair «Paimio N 41». Traditional Scandinavian bent wood skis. A. Aalto, A. Marcio vase «Savoy». Traditional trousers of the Sami and Lapps (Lapland).

\subsection{4 $4^{\text {th }}$ model - «Replacement of the national component by the international one»}

In this version, either an artificial choice of an international generalized component is assumed as the main one in shaping, or cases are assumed when the primordially national was completely destroyed, and the international becomes the main national component.

A striking example is the United States with an American multinational model with a dominant international link. The United States became the first engineered nation [15]. In the history of American design, we see an active influx of extravagant ideas and experiments tiffany, streamline, art deco, etc. However, all branches of experimentation merge into one organic design, or its modern interpretation, the so-called contemporary style. The original famous principle «form follows function» was thus constantly supplemented: the functions of things can be not only utilitarian, but also informational, cultural, sign, symbolic, technological, even cognitive. In the American model of design development, we observe constant influx of energy of shaping from different nations, constant synthesis and development of a complex or unified vector for the development of industrial design (fig. 6). 

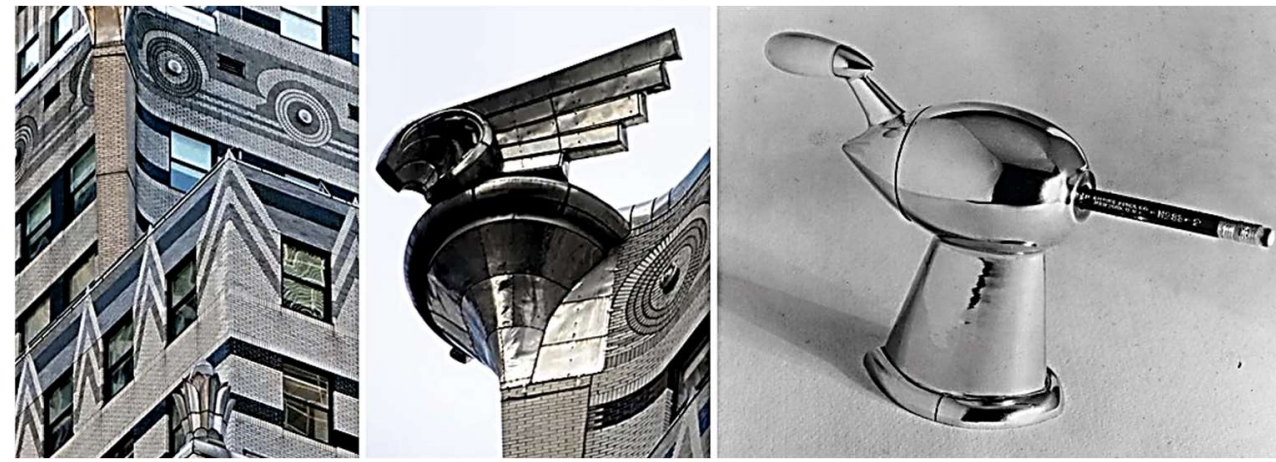

Fig. 6. Chrysler building. Raymond Loewy «pencil sharpener».

\subsection{5 $5^{\text {th }}$ model - «Conglomerate of international and national components»}

This model is a kind of antipode of the previous model. The whole history of human relationships is a continuous series of conquests of some peoples by others. And in this sense, it is interesting to study not only how the culture of the colonized people interacts with the colonizer, but also the reverse process. About this type of model, we can say that it is fully or partially realized when one national culture influences another national culture. Thus a new national model arises, which carries a conglomerate of characteristics of two or more nations. As an example - the colonial model (Australia, India, some regions of America and Africa). This is how a colonial design style arises, which goes from the East to the West and conquers Europe. Sometime it becomes very popular in European countries (fig. 7).
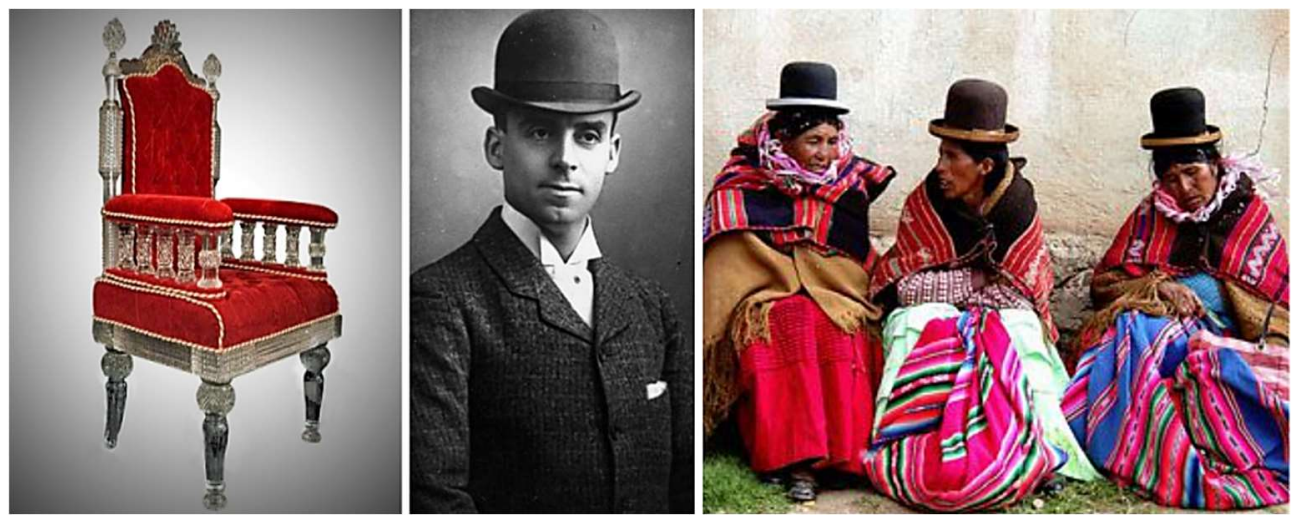

Fig. 7. F. and S. Osler «Glass armchair for Maharajah Saijan Singh». Bowler hat. Quechua Indian women today, Bolivia.

\subsection{6 $6^{\text {th }}$ model - «Autonomy of national and international components»}

This model is for countries where initially the national component is undoubtedly the most important element of shaping, but in the process of development of industrial production, it loses its influence. International and national trends in shaping are being developed almost autonomously, the priority remains with the first. Many European countries (Germany, England, and France) can be an example. As example the German design model, despite its versatility (modern, art deco, totalitarianism), still seems to be quite straightforward. At the same time, there is undoubtedly the emergence of some features that make German 
functionalism even more international and harmonious (streamline, bionics). This type shows us a clear vector of design development, with a precisely chosen pathway, often either limited by some factors or the style predisposition of the country. The traditions of functionalism have always been especially strong in this country. Functionalism is promoted as a national treasure, a special attitude towards design quality, safety, production technology, production efficiency, and ease of use is cultivated. German design has traditionally been associated with modernism and has come to be regarded as an «international style» (fig. 8).
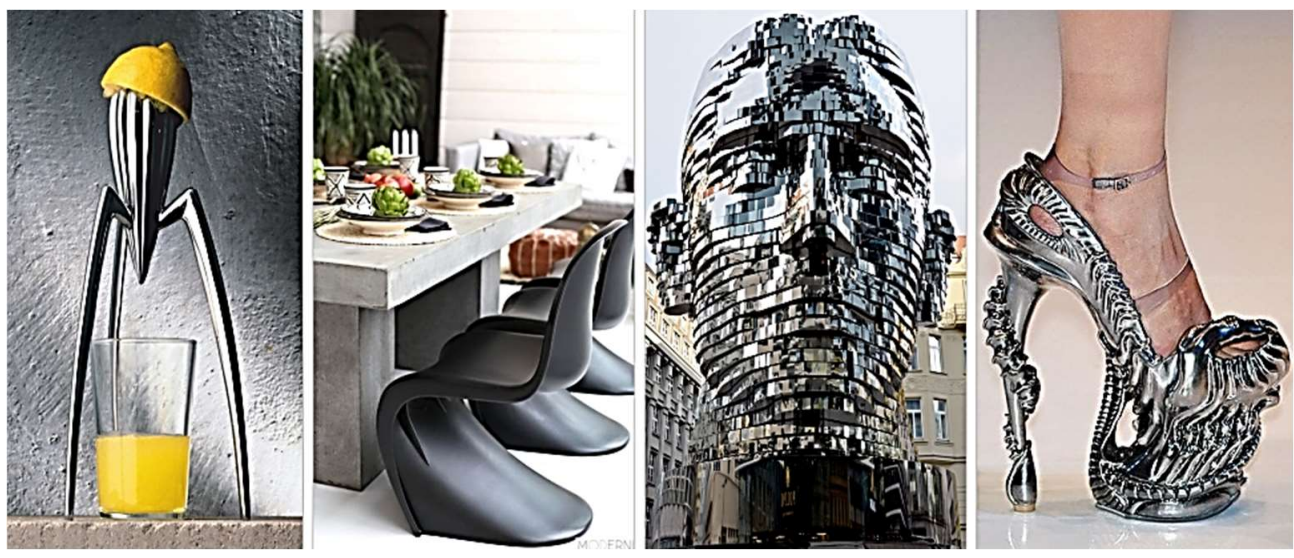

Fig. 8. Philippe Starck «Juicy Salif». Verner Panton «Panton Chaire». David Cerny «The Head of Franz Kafka». Alexander McQueen «VOSS».

\section{Conclusion}

The national component is a complex phenomenon in the history of design of the XX-XIX centuries, which is an important element in its evolution. The significance of the national component is not limited to national formation and folk artisanship, but has a much broader significance. It can contain the elements of industrial shaping, which later become the basis for the national originality of the design of a country or nation.

National and cultural issues in the history of design were considered from a phenomenological point of view. While it is proposed to consider the national component from an evolutionary point of view, as a phenomenon that has arisen, has passed a certain development path and has development trends in the future. The evolutionary development of the national component was facilitated by the following factors: socio-economic, scientific and technical, socio-cultural and artistic and stylistic.

As a result of the evolutionary development of the national component, it was possible to identify that the carrier of the national is shifting in the process of the development of society and its transition to the post-industrial stage from the subject-spatial environment to the human consumer. Latter in the post-industrial period, consumer forms their environment based on nationality, culture, country, individual characteristics and preferences.

The interaction of national and international components is reflected in certain trends that have been developed under the influence of a number of factors - socio-historical and economic phenomena, cultural and national characteristics, mentality, as well as achievements in the field of science and technology. This allows us to conclude that the national and international components can demonstrate different principles of interaction:

- continuity, organic interweaving of the national component into the international one;

- denial of the national component, the desire for abstraction, generalization, or parallel development; 
- return to the roots, rethinking traditions through new materials, technologies, a new look at the national.

The presented models of interaction between national and international components allow us to see the history of design development through the prism of a synergistic approach. This considers the history of design not only from a logical-historical point of view, but also allows us to see the national component not only as a phenomenon of individual nations, but also as a complex multicomponent model.

\section{References}

1. M. Filipová. Design and National Identity, Journal of Design History 30 (4), (2017). DOI: 10.1093/jdh/epx031.

2. J. Hadlaw. Design Nationalism, Technological Pragmatism and the Performance of Canadian-ness: The Case of the Contempra Telephone, Journal of Design History 32 (3), (2019). DOI: 10.1093/jdh/epz013.

3. J. Gimeno-Martínez. Designing Worlds: National Design Histories in the Age of Globalization Journal of Design History 31 (3), (2018). DOI: 10.1093/jdh/epy029.

4. J.M. Woodham. Design in the $20^{\text {th }}$ Century: Form Follows Function? Design in the $20^{\text {th }}$ Century: Nationalism and Internationalism Journal of Design History 7 (4), (1994). DOI: 10.1093/jdh/7.4.306.

5. St.N. John. Australian Communication Design History: An Indigenous Retelling, Journal of Design History 31 (3), (2018). DOI: 10.1093/jdh/epy014.

6. A. Pieris, M. Lozanovska. Industry + architecture: National narratives/international forces. Fabrications 29 (2), (2019). DOI: 10.1080/10331867.2019.1587129.

7. O. Semenyuk, N.A. Chernysh, Y.N. Khvan, R. Chekaeva, O.N. Tkach, B. Kassimova, A.D. Otarbayev. Trends in the development of national identity in architecture AnnalesAnali Za Istrske in Mediteranske Studije - Series Historia Et Sociologia 27 (3), (2017). DOI: 10.19233/ASHS.2017.36.

8. S. Pandya. Architecture in national identities: a critical review, National Identities 22 (4), (2020). DOI: 10.1080/14608944.2020.1812825.

9. T. Modood. National identity and ethnoreligious identity, Identities, (2020). DOI: 10.1080/1070289X.2020.1852794.

10. A. Agadjanian. From urban landscape to national culture: Russia's conspicuous religious simulacra and enduring, if fragile, secularity, Social Compass, (2021). DOI: 10.1177/0037768620985750.

11. T. Messell. Globalization and design institutionalization: ICSID's XI ${ }^{\text {th }}$ congress and the formation of ALADI, 1979 Journal of Design History 32 (1), (2019). DOI: 10.1093/jdh/epy040.

12. J. Kelly, C. Jamieson. Practice, discourse and experience: The relationship between design history and architectural history Journal of Design History 33 (1), (2020). DOI: 10.1093/jdh/epz045.

13. S. Mikhailov, A. Mikhailova, N. Nadyrshine. Multilinear approach to representing the historical evolution of urban design (industrial and post-industrial periods), IOP Conference Series: Materials Science and Engineering 890, 012006 (2020). DOI: 10.1088/1757-899X/890/1/012006.

14. D.J. Huppatz, G.Lees-Maffei. Why design history? A multi-national perspective on the state and purpose of the field, Arts and Humanities in Higher Education 12 (2-3), (2013). DOI: $10.1177 / 1474022212467601$.

15. J. Meroz, J. Gimeno-Martinez. Introduction: Beyond Dutch Design: Material Culture in the Netherlands in an Age of Globalization, Migration and Multiculturalism Journal of Design History 29 (3), (2016). DOI: 10.1093/jdh/epw019. 
16. M.R. Melchior. From Design Nations to Fashion Nations? Unpacking Contemporary Scandinavian Fashion Dreams Fashion Theory 15 (2), (2011). DOI: 10.2752/175174111X12954359478681.

17. A.V. Munch. On the outskirts: The geography of design and the self-exoticization of danish design Journal of Design History 30 (1), (2017). DOI: 10.1093/jdh/epw049.

18. A. Tollenaar, J. Meihuizen. No future without a past: The dutch national design archive (NDA), Journal of Design History 29 (3), (2016). DOI: 10.1093/jdh/epw032.

19. K. Fallan. Designing modern Norway: A history of design discourse Routledge, London (2016).

20. L. Kuleeva, T. Burova, L. Listovskaya, A. Ibragimova. Features of modern methods of forming embankments, IOP Conference Series Materials Science and Engineering 890, 012005 (2020). DOI: 10.1088/1757-899X/890/1/012005.

21. S. Mikhailov, R. Khafizov, A. Mikhailova, N. Nadyrshine, L. Nadyrshine. Supergraphics as a project and artistic method in design of a modern city, IOP Conference Series: Materials Science and Engineering 890, 012003 (2020). DOI: 10.1088/1757899X/890/1/012003.

22. G. Adamson, G. Riello, S. Teasley. Global design history Routledge, London (2011).

23. S. Berger. A Return to the National Paradigm? National History Writing in Germany, Italy, France, and Britain from 1945 to the Present, Journal of Modern History 77 (3), (2005). DOI: 10.1086/497719.

24. K. Fallan. Scandinavian Design: Alternative Histories Bloomsbury Academic, (2012).

25. K. Fallan, G. Lees-Maffei. Introduction: Made in Italy. Rethinking a Century of Italian Design 133 , Bloomsbury Academic, (2014).

26. A. Mikhailova, Husnutdinova L. Evolution of the national component in industrial design Vestnik OSU 5 (180), (2015).

27. A. Mikhailova, L. Husnutdinova. Trends in implementation and the international component in the history of design of the XX-XXI centuries, MGHPA Bulletin 1, (2020).

28. A. Mikhailova. National design models, Design Review 3-4, (2013).

29. S. Mikhailov, A. Mikhailova. Design history. Short course: Tutorial Moscow, Publishing House «Union of Designers of Russia», (2004).

30. S. Mikhailov, A. Mikhailova. Fundamentals of design: A textbook for universities Kazan: Publishing House «Design-kvartal», (2008).

31. S. Mikhailov. Design history. Volume 1: Textbook for universities Moscow, Publishing House «Union of Designers of Russia», (2002).

32. S. Mikhailov. Design history. Volume 2: Textbook for universities Moscow, Publishing House «Union of Designers of Russia», (2004).

33. A. Lavrentiev. Design History: a textbook Moscow, Publishing House «Gardariki», (2007).

34. F. Ibragimova. Features of the formation of the Japanese school of shaping in the context of the world history of design (1868-1945), Design Review 1-2, (2011). 